\title{
Night-time feeding of Bmal1-l- mice restores SCFA rhythms and their effect on ghrelin
}

\author{
Anneleen Segers, Louis Desmet, Shu Sun, Kristin Verbeke, Jan Tack and Inge Depoortere \\ Translational Research Center for Gastrointestinal Disorders, KU Leuven, Leuven, Belgium
}

Correspondence should be addressed to I Depoortere: inge.depoortere@kuleuven.be

\begin{abstract}
The known crosstalk between short-chain fatty acids (SCFAs) and the circadian clock is tightly intertwined with feeding time. We aimed to investigate the role of the core clock gene Bmal1 and feeding time in the diurnal rhythms in plasma and caecal SCFA levels and in their effect on the release of the hunger hormone ghrelin in the stomach and colon. WT, Bmal1\% (ad libitum fed) and night-time-restricted-fed (RF)-Bmal1\% littermates were killed at zeitgeber time (ZT) 4 and 16. SCFA concentrations were measured by gas chromatography. To investigate the effect of SCFAs on ghrelin release, stomach and colonic full-thickness strips were incubated with Krebs or a SCFA mix mimicking plasma or caecal concentrations, after which octanoyl ghrelin release was measured by RIA. Diurnal rhythms in caecal and plasma SCFAs oscillated in phase but rhythmic changes were abolished in Bmal1\% mice. RF of Bmal1-\% mice restored fluctuations in caecal SCFAs. Plasma SCFA concentrations failed to affect gastric ghrelin release. The effect of caecal SCFA concentrations on colonic ghrelin release was rhythmic (inhibition at ZT 4, no effect at ZT 16). In Bmal1\%- mice, the inhibitory effect of SCFAs at ZT 4 was abolished. RF Bmal1\% mice restored the inhibitory effect and increased colonic Clock expression. To conclude, diurnal fluctuations in caecal SCFAs and the effect of SCFAs on colonic ghrelin release are regulated by feeding time, independent of the core clock gene Bmal1. However, local entrainment of other clock genes might contribute to the observed effects.
\end{abstract}

\section{Key Words}

- night-time restricted feeding

- circadian clock

- short-chain fatty acids

- ghrelin

\section{Introduction}

Ghrelin, a 28-amino acid peptide, is the only known circulating hormone that stimulates food intake (Kojima et al. 1999). Ghrelin is mainly produced in the stomach and is acylated by ghrelin O-acyltransferase (GOAT) on Ser ${ }^{3}$, which is essential for its physiological functions (Gutierrez et al. 2008, Yang et al. 2008). Besides activation of orexigenic neural circuits, ghrelin has numerous other physiological effects, including regulation of glucose metabolism, stimulation of gut motility and gastric acid secretion, and modulation of sleep, taste sensation and reward-seeking behaviour (Avau et al. 2013, Müller et al. 2015).
In humans, plasma ghrelin levels increase before a regularly timed meal and decrease to trough levels within $1 \mathrm{~h}$ after eating (Cummings et al. 2001). Furthermore, plasma ghrelin levels show a 24-h diurnal rhythm in both humans and rodents, reaching peak values during their resting phase (Bodosi et al. 2004, Yildiz et al. 2004, Laermans et al. 2015). Diurnal rhythms in plasma ghrelin levels and gastric ghrelin expression are abolished in mice that lack the core clock gene Bmal1, indicating that ghrelin levels are regulated by the circadian clock (Laermans et al. 2015). 
The circadian clock aligns behavioural patterns with the solar day, anticipating the body's metabolic needs (Reinke \& Asher 2019). The master clock, located in the suprachiasmatic nucleus, is synchronized or entrained by the light-dark cycle. Circadian rhythms are maintained by a set of core clock genes that form transcription-translation feedback loops in which they not only regulate their own transcription but that of many clock-controlled genes. The CLOCK-BMAL1 heterodimer forms the positive loop, while period (PER1, PER2, and PER3) and cryptochrome (CRY1 and CRY2) genes form the negative loop (Partch et al. 2014). Animals with mutations or ablations of these core clock genes have altered food intake patterns, body weight and metabolism (Laermans \& Depoortere 2016).

The master clock synchronizes the rhythm of peripheral clocks present in the liver, gastrointestinal tract, adipose tissue and numerous other tissues and organs (Mohawk et al. 2012). However, peripheral circadian rhythms are also regulated by local entrainment signals or 'zeitgebers', such as the timing of meals (Panda 2016). Desynchronizing these zeitgebers by, for example, rotating shift work or frequent flying misaligns master and peripheral clocks, causing chronodisruption (Dibner 2020). Night work and obesity are associated with loss of diurnal rhythmicity of plasma ghrelin levels, altered ghrelin cell sensitivity and blunted post-meal suppression of ghrelin (Yildiz et al. 2004, Crispim et al. 2011, SchiavoCardozo et al. 2013, Vancleef et al. 2018, Wang et al. 2019). This might play a role in the development of metabolic diseases, which are prevalent in chronodisrupted individuals (Karlsson et al. 2001, Pan et al. 2011, Laermans \& Depoortere 2016).

The post-meal suppression of ghrelin levels is dependent on the caloric content and type of ingested nutrients (Callahan et al. 2004, Foster-Schubert et al. 2008). The sensing of these nutrients is likely mediated by different chemosensory receptors that are present on ghrelin cells (Hass et al. 2007, Janssen et al. 2011, 2012, Vancleef et al. 2015, 2018, Steensels \& Depoortere 2018). Surprisingly, the short-chain fatty acid (SCFA) receptor free fatty acid receptor 2 (FFAR2) is highly expressed on gastric ghrelin cells. Engelstoft et al. showed that SCFAs inhibited ghrelin secretion in mouse primary gastric mucosal cells, mainly through FFAR2 and a $\mathrm{G \alpha}_{\mathrm{i} / \mathrm{o}}$ mechanism. However, other studies using isolated gastric ghrelin cells and a ghrelinoma cell line failed to show an effect of SCFAs on ghrelin release (Lu et al. 2012, Engelstoft et al. 2013, Koyama et al. 2016). It is currently unknown whether plasma SCFA concentrations are high enough to activate FFAR2 on gastric ghrelin cells. Nevertheless, ghrelin is also expressed in more distal regions such as the colon where bacterial fermentation of dietary carbohydrates in the caecum and colon takes place and results in higher concentrations of SCFAs. Therefore, the effects of SCFAs on ghrelin release might be more pronounced in the colon. SCFAs are an important energy source for the host, but are also key signalling molecules that propagate beneficial metabolic effects (Koh et al. 2016).

Additionally, SCFAs can entrain peripheral circadian rhythms in the host (e.g. liver) by adjusting peripheral clock gene expression (Leone et al. 2015, Tahara et al. 2018). In turn, the circadian clock can regulate the diurnal rhythm in the levels of fecal SCFAs, SCFA receptor expression and their functional effects (Mukherji et al. 2013, Segers et al. 2019).

In the present study, we aimed to investigate whether (1) plasma and caecal SCFAs levels show a diurnal rhythm and affect ghrelin release in the stomach and colon in a circadian manner, respectively; (2) the diurnal fluctuations of SCFAs and their rhythmic effects on ghrelin release are dampened by deletion of the core clock gene Bmal1; (3) the loss in the day/night food intake pattern induced by deletion of Bmal1 are the trigger for the loss in rhythmicity and can be restored by 2 weeks of night-time restricted feeding.

\section{Materials and methods}

\section{Mice studies}

\section{Mice}

C57BL/6J mice were purchased from Janvier Labs (Le Genest Saint Isle, France). Bmal1+/- mice (kindly provided by R Lijnen, KU Leuven, Leuven, Belgium) (Hemmeryckx et al. 2011) were bred in the animal facility of the KU Leuven to generate Bmal1 $\%$ and wild type (WT) littermates and were genotyped by PCR on total genomic DNA from the ear. Mice had ad libitum access to chow and drinking water unless otherwise specified and were housed in a temperature-controlled environment under a $12 \mathrm{~h} / 12 \mathrm{~h}$ light/dark-cycle (zeitgeber time (ZT) $0=$ lights on). All experiments were approved by the Ethical Committee for Animal Experiments of the KU Leuven and carried out in accordance with the approved guidelines.

\section{Experimental design}

C57BL/6J mice (male, age 12-15 weeks) were killed over the course of $24 \mathrm{~h}$ at 4 -h intervals. Ad libitum fed Bmal1\% and WT littermates (male) were killed at ZT 4 
(resting phase) and 16 (active feeding phase) at age 12-16 weeks, as Bmal1-/- mice older than 16 weeks show growth retardation (Kondratov et al. 2006). To study the effect of restoration of diurnal rhythmicity in food intake, a group of Bmal1 $\%$ mice was only fed (ad libitum) during the night for 2 weeks (From ZT 12 to ZT 24; Bmal1/- RF) prior to the day of killing. On the day of killing, Bmal1 $\%$ RF mice were killed at ZT 4 (fasted from ZT 0-4) and 16 (fed from ZT 12-16).

Luminal content of the caecum and stomach and/or plasma were collected to measure SCFA concentrations. The stomach and proximal colon were removed for ghrelin release experiments. The mucosa of the proximal colon was stored in RNAlater (Qiagen) and processed for quantitative real-time PCR (qRT-PCR).

\section{Analysis of total SCFA concentrations in chyme, faeces and plasma}

Total SCFA concentrations in luminal content of the caecum and stomach were determined as previously described (Lu et al. 2012). Plasma samples were acidified using $\mathrm{HCl}$ after addition of a mixture of $\left[{ }^{2} \mathrm{H}_{3}\right]$-acetate, $\left[{ }^{2} \mathrm{H}_{5}\right]$-propionate and $\left[{ }^{2} \mathrm{H}_{7}\right]$-butyrate as internal standard. SCFAs were converted to their respective 2,4-difluoroanilides by addition of 2,4-difluoroaniline and 1,3-dicyclohexylcarbodiimide and extracted to ethyl acetate in the presence of $\mathrm{NaHCO}_{3}$. The supernatant was added to a micro-insert (VWR International, Radnor, PA, USA) and analysed on a TRACE 1300 Gas Chromatograph coupled to a DSQ II Mass Spectrometer (Thermo Fisher Scientific), equipped with an analytical column (Restek Stabilwax-DA column; Restek, Bellefonte, PA, USA) of $30 \mathrm{~m} \times 0.25 \mathrm{~mm}$ i.d. and $0.25 \mu \mathrm{m}$ film thickness.

\section{Measurement of ghrelin release from intestinal full-thickness strips}

Eight full-thickness strips of the corpus of the stomach $( \pm 5 \times 5 \mathrm{~mm})$ and two full-thickness strips of the whole proximal colon were dissected and incubated with $1 \mathrm{~mL}$ Krebs-buffer or Krebs-buffer containing a SCFA mix mimicking peak plasma (acetate: $348 \mu \mathrm{M}$, propionate: $9 \mu \mathrm{M}$, butyrate: $3 \mu \mathrm{M}$ ) or peak caecal (acetate: $85 \mathrm{mM}$, propionate: $8 \mathrm{mM}$, butyrate: $31 \mathrm{mM}$ ) concentrations. Strips were incubated for $2 \mathrm{~h}$ at $37^{\circ} \mathrm{C}, 5 \% \mathrm{CO}_{2}$, and $10 \mu \mathrm{L}$ of $57 \mathrm{mM}$ protease inhibitor phenylmethylsulfonyl fluoride was added at the start and after $1 \mathrm{~h}$ of incubation. The release of octanoyl ghrelin in the medium was measured by radioimmunoassay (RIA). Tissue strips were dried to correct the ghrelin release for dry tissue weight of the strip.

\section{Cell line studies}

\section{Cell culture}

The MGN3-1 ghrelinoma cell line was kindly provided by Iwakura et al. (2010). Cells were cultured in DMEM supplemented with $10 \%$ foetal bovine serum and $1 \%$ penicillin $(100 \mathrm{U} / \mathrm{mL})$ and streptomycin $(100 \mathrm{mg} / \mathrm{mL})$ at $37^{\circ} \mathrm{C}$ in $5 \% \mathrm{CO}_{2}$.

\section{SCFA-stimulated ghrelin release}

Cells were incubated for $1 \mathrm{~h}\left(37^{\circ} \mathrm{C}, 5 \% \mathrm{CO}_{2}\right)$ with Krebsbuffer or Krebs-buffer containing SCFA mixes mimicking concentrations in plasma, stomach or caecum. Acetate, propionate and butyrate concentrations used were 3489-3 $\mu \mathrm{M}$ (plasma), 12-4-0.2 mM (stomach) and 85-8-31 mM (caecum), respectively. The release of octanoyl ghrelin in the medium was measured by RIA.

\section{Ghrelin radioimmunoassay}

Cell and tissue culture supernatants were acidified (10\% $1 \mathrm{M} \mathrm{HCl}$ ), extracted on a Sep-Pak C18 column (Waters Corporation, Milford, MA, USA) and vacuum-dried. The RIA for octanoyl ghrelin was performed as previously described (Janssen et al. 2011).

\section{Quantitative real-time PCR (qRT-PCR)}

RNA was isolated using the RNeasy Mini kit (Qiagen). RNA was reverse transcribed to cDNA using the HighCapacity cDNA Reverse Transcription kit (Thermo Fisher Scientific). qRT-PCR was performed using the Lightcycler 480 with the Lightcycler 480 Sybr Green I Master mix (Roche Diagnostics). Results were corrected for interrun variability and expressed relative to the geometric mean of the normalized expression of three stable housekeeping genes ( $\beta$-actin, Ppib and Hmbs) that do not show a circadian rhythm (Vandesompele et al. 2002). Primer sequences are listed in Table 1.

\section{Statistics}

Diurnal rhythms were analysed using the free Cosinor software (version 3.1, R. Refinetti, Boise State University, Boise, ID, USA), which determines the best-fitting cosine curve (diurnal: period $=24 \mathrm{~h}$; ultradian: period $=12 \mathrm{~h}$ ) for a data set using the cosinor procedure as described by Nelson et al. (1979). Since all data collected in Bmal1-/mice and their WT littermates and MGN3-1 ghrelin release experiments was distributed in a non-normal and/or 
Table 1 Primer sequences.

\begin{tabular}{l} 
Gene \\
\hline$\beta$-actin \\
Clock \\
Hmbs \\
Per2 \\
Ppib \\
Reverb $\alpha$
\end{tabular}

\begin{tabular}{l}
\hline Forward primer \\
\hline GATCTGGCACCACACCTTCTAC \\
TCTACAGAAGAGCATTGATTTTTTC \\
CTGAAGGATGTGCCTACCATAC \\
GATGACAGAGGCAGAGCACAAC \\
GGAGATGGCACAGGAGGAAA \\
CCCTGGACTCCAATAACAACACA \\
\hline
\end{tabular}

\begin{tabular}{l}
\hline Reverse primer \\
\hline TGGATGGCTACGTACATGGCTG \\
TCATTACTAAGGAATGTGGGTTTCC \\
AAGGTTTCCAGGGTCTTTCC \\
TTTGTGTGCGTCAGCTTTGG \\
CCCGTAGTGCTTCAGCTTGAA \\
GCCATTGGAGCTGTCACTGTAG
\end{tabular}

non-homogeneous manner, log-transformed data was used for all further analyses. Student's $t$-test was performed to detect differences in SCFA concentrations in stomach chyme of WT mice between ZT 4 and 16. Differences in SCFA concentrations, in ghrelin release from MGN3-1 cells and from stomach and colon strips, and in clock gene expression between different time points and groups were analysed using a mixed model analysis (SAS Studio University Edition 9.4, SAS Institute Inc., Cary, NC, USA). Significance was accepted at the 5\% level. Results are presented as back-transformed mean \pm s.E.M.

\section{Results}

\section{Diurnal fluctuations in plasma, caecal and stomach SCFA concentrations}

The diurnal rhythm of SCFA concentrations was investigated in the plasma and luminal content of the caecum of C57BL/6J mice, killed over the course of $24 \mathrm{~h}$ (4-h interval).

Plasma acetate, propionate and butyrate concentrations all showed a diurnal rhythm of $24 \mathrm{~h}$ $(P<0.05)$, peaking at ZT 21h02, ZT 19h09 and ZT 20h20, respectively (Fig. 1A). Caecal acetate and butyrate concentrations peaked at ZT $19 \mathrm{~h} 43$ and ZT $19 \mathrm{~h} 52$ $(P<0.01)$, respectively, while propionate concentrations showed an ultradian rhythm (period of $12 \mathrm{~h}, P<0.001$ ), peaking at ZT 3h52 and 15h52 (Fig. 1B).

Total SCFA concentrations in plasma peaked at ZT 20h51, in phase with the rhythms of total SCFA concentrations in the caecum (peak at ZT 19h40), but not with the distal colon, whereas in a previous study (Segers et al. 2019) we have shown that total SCFA concentrations peaked at ZT 5 h57 (Fig. 1C).

Average SCFA concentrations in plasma were 294-fold lower than in the caecum $(341 \pm 20 \mu \mathrm{M}$ vs $101 \pm 4 \mathrm{mM})$. SCFAs were also detected in the luminal content of the stomach of WT mice $(21 \pm 4 \mathrm{mM})$ and were 60 -fold higher than in the plasma $(341 \pm 20 \mu \mathrm{M})$. Furthermore, stomach SCFA concentrations were 1.6-fold higher in the resting phase (ZT 4) compared to the active feeding phase (ZT 16) $(P<0.05$; Fig. 1D).

\section{Diurnal effects of SCFAs on ghrelin release}

\section{Concentration-dependent effects of SCFAs on ghrelin release from a ghrelinoma cell line (MGN3-1)}

The effect of SCFA mixes mimicking plasma, stomach and caecal concentrations on octanoyl ghrelin release from MGN3-1 gastric ghrelinoma cells was measured. While plasma $(360 \mu \mathrm{M})$ and stomach $(16 \mathrm{mM})$ SCFA concentrations did not affect octanoyl ghrelin release, caecal concentrations (124 mM) stimulated octanoyl ghrelin release $(P<0.001$, Fig. $2 \mathrm{~A})$.
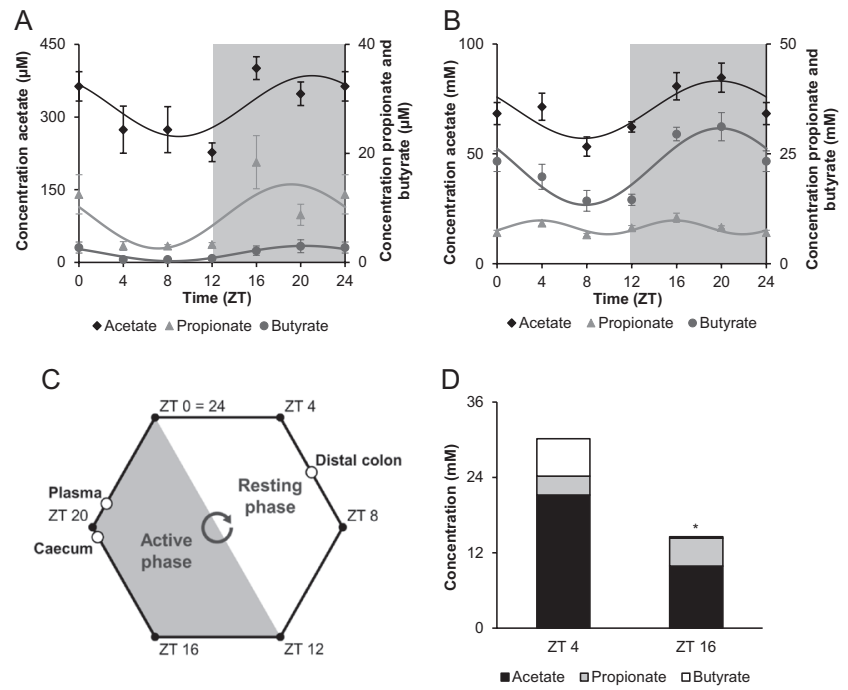

Figure 1

Diurnal fluctuations in plasma, caecal and stomach SCFA concentrations. (A and B) Diurnal fluctuations in SCFA concentrations in plasma (A) and in the luminal content of the caecum (B) of C57BL/6J mice. The fitted cosine curves determined by cosinor analysis are shown. Light and dark phases are shaded in white and grey respectively ( $n=7-8$ mice/time point). (C) Acrophase comparison of SCFA concentrations in plasma and in the luminal content of caecum and distal colon (Segers et al. 2019) of C57BL/6J mice. (D) SCFA concentrations in the luminal content of the stomach of WT mice ( $\mathrm{N}_{\mathrm{ZT} 4}=5$ mice, $\mathrm{N}_{\mathrm{ZT} 16}=8$ mice). 

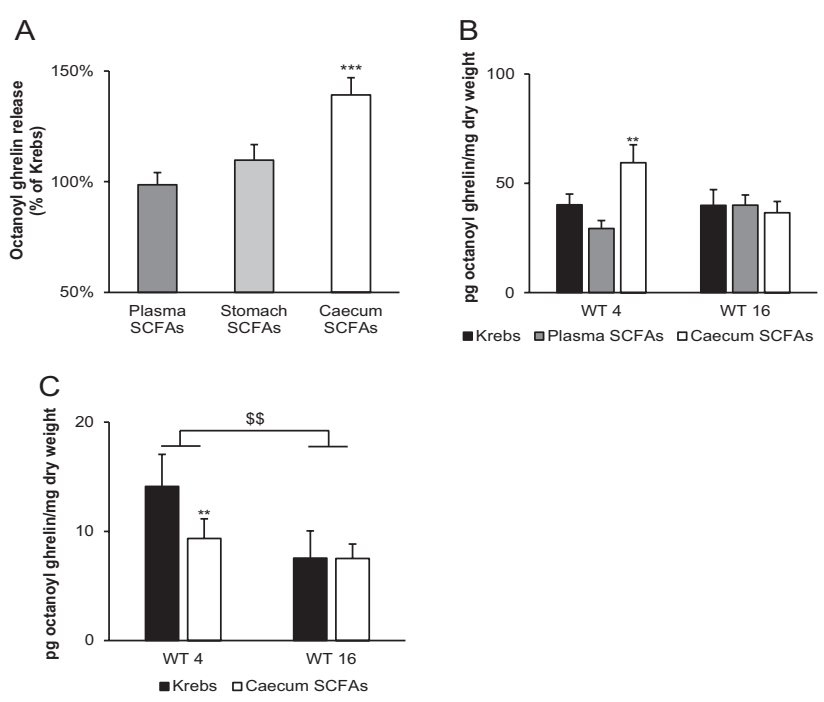

Figure 2

Diurnal fluctuations in SCFA-stimulated octanoyl ghrelin release. (A) Octanoyl ghrelin release of MGN3-1 cells after 1-h stimulation with SCFA mixes mimicking plasma $(360 \mu \mathrm{M})$, stomach $(16 \mathrm{mM})$ and caecal (124 mM) SCFA concentrations. ${ }^{*} * P<0.001$ compared to Krebs $(n=3-7$ independent experiments, $n=24-35$ wells/stimulus). (B and C) Octanoyl ghrelin release of full-thickness strips from the stomach (B) and proximal colon (C) after a 2-h stimulation with Krebs or a SCFA mix mimicking plasma $(360 \mu \mathrm{M})$ and caecal $(124 \mathrm{mM})$ concentrations at ZT 4 and 16. $* \star P<0.01$ compared to Krebs. ${ }^{\$ \$} P<0.01$, interaction effect (treatment * ZT) ( $n=8$ mice/time point, $n_{\text {stomach }}=14-31$ strips $/$ stimulus/ time point, $n_{\text {colon }}=8$ strips/stimulus/time point).

Time- and concentration-dependent effects of SCFAs on ghrelin release from stomach and colon strips

The effect of SCFAs on octanoyl ghrelin release from stomach full-thickness strips from WT mice killed in the resting phase (ZT 4) and active feeding phase (ZT 16) was investigated.

The SCFA mix mimicking plasma concentrations (360 $\mu \mathrm{M})$ had no effect on octanoyl ghrelin release from stomach strips at both ZTs. However, the SCFA mix mimicking caecal concentrations $(124 \mathrm{mM})$ stimulated octanoyl ghrelin release at ZT $4(P<0.01)$ and had no effect at ZT 16 , resulting in a significant $(P<0.01)$ interaction effect (Fig. 2B).

In the proximal colon, the SCFA mix mimicking caecal concentrations affected octanoyl ghrelin release at ZT 4 and not at ZT 16 (Fig. 2C). However, in contrast to the stomach, the SCFA mix inhibited octanoyl ghrelin release from the proximal colon $(P<0.01)$.

\section{Role of the clock gene Bmal1 in the rhythm of SCFAs and their diurnal effects on ghrelin release}

To study the role of the circadian clock in the diurnal fluctuations of SCFA concentrations, plasma and caecal
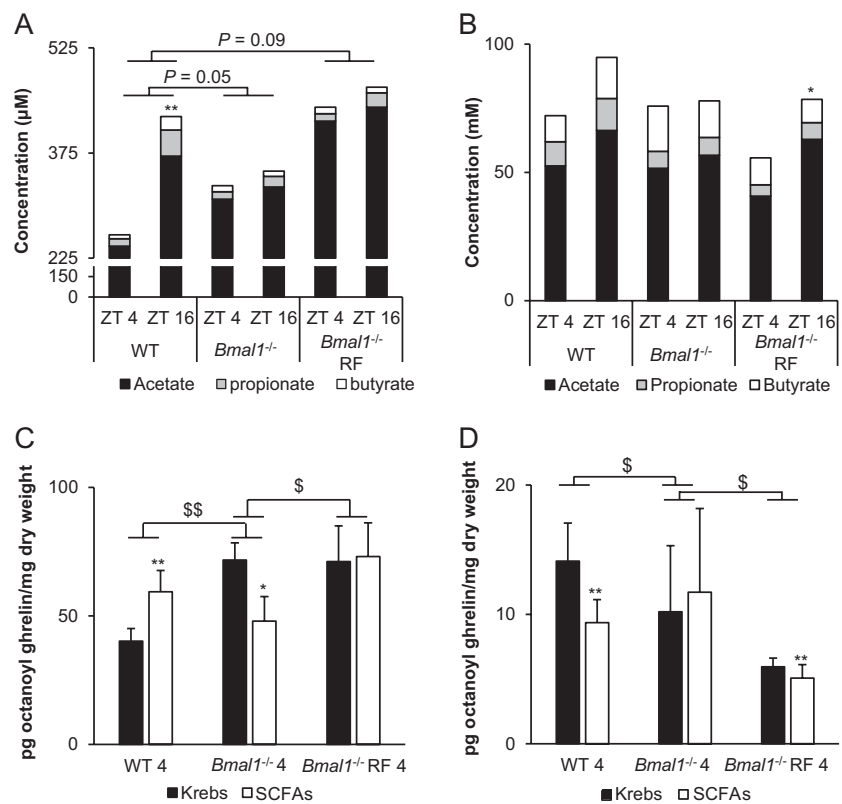

\section{Figure 3}

Effect of the clock gene Bmal1 and of night-time restricted feeding of Bmal1\% mice (Bmal1- RF) on diurnal fluctuations in SCFA concentrations and of SCFA-stimulated octanoyl ghrelin release. (A and B) SCFA concentrations in plasma $(A)$ and luminal content of the caecum $(B)$ of WT, Bmal1 $1-$ and Bmal1 $/$ RF mice at ZT 4 and 16. $* P<0.05, * * P<0.01$ compared to ZT 4 ( $n=8-10$ mice/group/time point). (C and D) Octanoyl ghrelin release of full-thickness strips from the stomach (C) and proximal colon (D) of WT, Bmal1\% and Bmal1\% RF mice after a 2-h stimulation with Krebs or SCFAs (124 mM) at ZT $4 . * P<0.05, * \star P<0.01$ compared to Krebs. ${ }^{\$} P<0.05, \$ \$ P<0.01$, interaction effect (treatment * group) ( $n=7-10$ mice/group, $n_{\text {stomach }}=14-38$ strips/stimulus/group, $n_{\text {colon }}=6-8 \mathrm{strip} /$ stimulus/group).

SCFA levels were measured in arrhythmic Bmal1/- mice and their WT littermates at ZT 4 and 16. Similar to C57BL/6J mice, total plasma SCFA concentrations were significantly $(P<0.01)$ higher in WT littermates at ZT 16 compared to ZT 4, total caecal concentrations showed a similar trend $(P=0.12)$. These differences were abolished in Bmal1 $\%$ mice. (Fig. 3A and B).

The caecal SCFA mix stimulated octanoyl ghrelin release from the stomach of WT mice at ZT 4 . In contrast, in Bmal1/- mice, this SCFA mix inhibited octanoyl ghrelin release $(P<0.05)$ (Fig. $3 \mathrm{C})$. In the proximal colon of WT mice, the SCFA mix inhibited octanoyl ghrelin release at ZT 4. In Bmal1\% mice, the SCFA mix had no effect on octanoyl ghrelin release (Fig. 3D).

\section{Restoration of diurnal fluctuations in SCFAs and of SCFA-stimulated ghrelin release in $\mathrm{Bmal1-/-} \mathrm{RF}$}

Since Bmal1 $\%$ mice eat continuously and hence do not show the typical day/night feeding rhythm 
(Laermans et al. 2015), we aimed to investigate whether the loss of rhythms in SCFA concentrations and of the effects of SCFAs on ghrelin release was due to their altered food intake pattern. A group of Bmal1 ${ }^{-}$mice was only fed during the dark phase for 2 weeks (Bmal1/- RF). Food intake was measured daily and body weight was measured every 3 days. Food intake and body weight were stable during night-time restricted feeding (Supplementary Figure $1 \mathrm{~A}-\mathrm{B}$, see section on supplementary materials given at the end of this article). Body weight at killing (ZT 4) was higher in Bmal1- RF compared to ad libitum fed Bmal1-- mice (Supplementary Figure 1C). Both ad libitum and RF-fed Bmal1 $\%$ mice weighed less than WT mice at killing.

Restricting the access of Bmal1-/- mice to food to the dark phase (Bmal1-/ RF) restored fluctuations in SCFA concentrations in the caecum $(P<0.05)$, but not in the plasma (Fig. 3A and B).

The inhibitory effect of SCFAs on octanoyl ghrelin release from the stomach of ad libitum-fed Bmal1- mice was abolished by RF (Figure 3C), while in the proximal colon RF restored the inhibitory effect observed in WT mice $(P<0.01$; Figure 3D).

\section{Effect of night-time restricted feeding of $\mathrm{Bmal1//-}$ mice on colonic clock gene expression}

Finally, we investigated whether night-time restricted feeding of Bmal1 $1-$ mice could affect circadian clock gene expression in the colonic mucosa at ZT 4, despite the absence of the core clock component BMAL1. While Clock mRNA expression was not different between WT and Bmal1-- mice, it was significantly upregulated in RF Bmal1 $/$ - mice $(P<0.001)$. Per 2 and Reverb $\alpha$ mRNA expression was higher and lower in Bmal1 1 - mice compared to WT mice, respectively $(P<0.001)$, but was not affected by RF of Bmal1\%- mice (Fig. 4).

\section{Discussion}

In the present study, we showed that plasma, stomach and caecal SCFA concentrations fluctuated diurnally. For the SCFAs in the plasma and luminal content of the caecum, the peak of the rhythm occurred at the end of the active phase while for the distal colon SCFAs peaked in the resting phase. Plasma SCFA concentrations did not affect gastric octanoyl ghrelin release, while caecal concentrations of SCFAs only affected octanoyl ghrelin release from stomach and colon in the resting phase (ZT 4) and had no effect in the active phase (ZT 16).
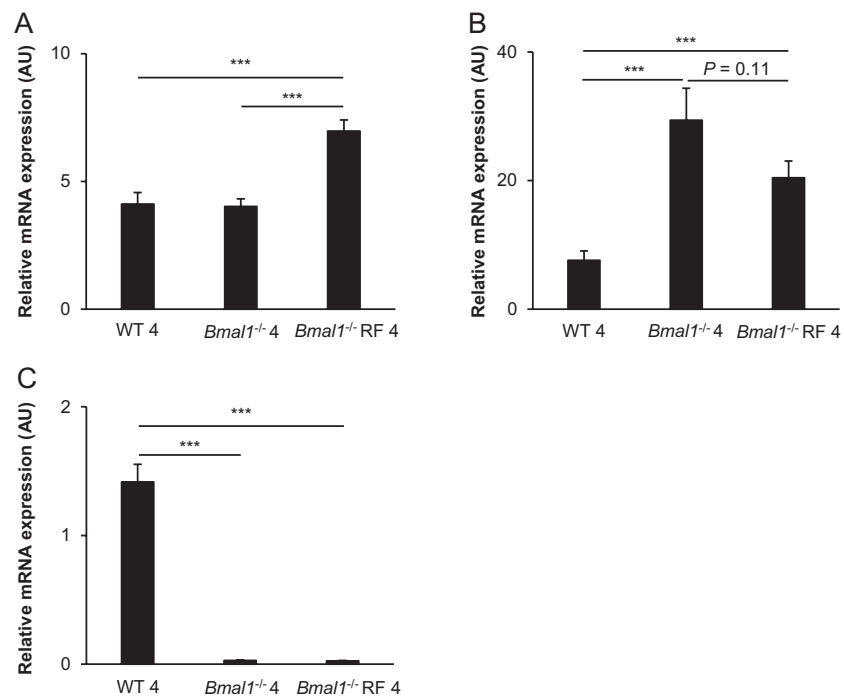

\section{Figure 4}

Effect of night-time restricted feeding of Bmal1- mice (Bmal1- RF) on clock gene expression in colonic mucosa. Clock (A), Per2 (B) and Reverb $\alpha$ (C) mRNA expression in the mucosa from the proximal colon of WT, Bmal1 $1-$ and Bmal1 ${ }^{-1-}$ RF mice at ZT 4. ${ }^{* * *} P<0.001$ ( $n=6-10$ mice/group).

Finally, we showed that night-time restricted feeding restored diurnal fluctuations in caecal SCFA concentrations and the effect of SCFAs on colonic octanoyl ghrelin release in Bmal1 $\%$ mice. However, night-time restricted feeding enhanced the expression of other clock genes (Clock) expressed in the colonic mucosa, which might contribute to the restoration of the rhythm.

In WT mice, total plasma SCFA concentrations showed a 24-h rhythm with a peak in the active phase, in phase with the rhythms of caecal SCFA concentrations. SCFAs in the distal colon peaked $10 \mathrm{~h} 17$ after the acrophase of SCFAs in the caecum. This delay might partially be caused by the transit time from the caecum to the distal colon, which has previously been shown to be 5-6 h (Padmanabhan et al. 2013). Consequently, SCFAs in the plasma mainly originate from the caecum, the main site of microbial SCFA production (den Besten et al. 2013).

Interestingly, average SCFA concentrations in the stomach content of WT mice reached $21 \pm 4 \mathrm{mM}$. The measured acetate and propionate in the chyme might have originated from the chow, since we measured $25 \mathrm{mmol} / \mathrm{kg}$ acetate and $30 \mathrm{mmol} / \mathrm{kg}$ propionate in the chow (butyrate under detection limit; mouse maintenance diet (Ssniff Spezialdiäten GmbH, Soest, Germany)). However, the presence of butyrate in the luminal content of the stomach indicates that coprophagic behaviour might have also contributed to the measured SCFA concentrations. Coprophagic behaviour has been shown to peak at the start of the resting phase (ZT 0 -4) (Ebino 1993). 
This corresponds to the increased SCFA concentrations at ZT 4 compared to ZT 16 . In addition, local bacterial production of SCFAs cannot be excluded since the anterior part of the stomach of rodents is known to harbour a large population of microorganisms at a $\mathrm{pH}$ that permits bacterial multiplication (Smith 1965).

Although SCFA concentrations in the stomach were 60 times higher than in the plasma, neither concentrations affected octanoyl ghrelin release from gastric ghrelinoma cells. Only caecal levels of SCFAs (124 mM) could stimulate octanoyl ghrelin release. It is unlikely that these concentrations reach gastric ghrelin cells in vivo. Previous studies have shown that FFAR2 and FFAR3 are highly expressed on gastric brush cells around the limiting ridge. This chemosensory cluster has been suggested to convey signals to closely associated ghrelin cells and might play a role in the effect of SCFAs on gastric ghrelin release in vivo (Hass et al. 2007, Eberle et al. 2014). However, we found that the SCFA mix mimicking plasma concentrations also failed to affect octanoyl ghrelin release from stomach full-thickness strips, which contain brush cells. The SCFA mix mimicking caecal concentrations stimulated octanoyl ghrelin release at ZT 4 and had no effect at ZT 16 , indicating that the effect of SCFAs on ghrelin release is time-dependent.

It remains to be determined whether these findings are representative for possible effects of SCFAs on human gastric ghrelin cells. SCFAs can be present in food (e.g. in vinegar and other fermented food, as preservatives and in dairy products) (EFSA 2014, Ho et al. 2017, McNabney \& Henagan 2017). However, their concentrations in the human stomach are likely lower and much more variable (both intra- and inter-individual).

Although ghrelin is mainly produced in the stomach (Kojima et al. 1999), we found that at ZT 4, basal octanoyl ghrelin release from the proximal colon was only three times lower compared to release from the gastric corpus. Colonic ghrelin release might therefore significantly contribute to plasma octanoyl ghrelin levels. We previously showed that SCFAs had maximal effect on proximal colon contractility at ZT $4 \mathrm{~h} 17$, in phase with diurnal SCFA concentrations in the distal colon (Segers et al. 2019). Accordingly, we hypothesized that the effect of SCFAs on octanoyl ghrelin release from the proximal colon would also peak around ZT 4 . Indeed, the SCFA mix only affected octanoyl ghrelin release at ZT 4 and not at ZT 16. However, in contrast to the stomach, the SCFA mix inhibited octanoyl ghrelin release from the proximal colon. The opposite findings of the effect of SCFAs on ghrelin release between stomach and colon might be due to activation of different signalling pathways by activation of FFAR2, as FFAR2 can be coupled both to the stimulatory $\mathrm{G} \alpha_{\mathrm{q}}$ or the inhibitory $\mathrm{G} \alpha_{\mathrm{i}}$ pathway (Le Poul et al. 2003). Additionally, SCFAs might affect release of gastric- or colon-specific hormones (Koh et al. 2016), that in turn influence local ghrelin release.

Increasing microbial SCFA production by increasing fibre intake has been linked with decreased plasma ghrelin concentrations in humans and rats (Cani et al. 2004, Tarini \& Wolever 2010, Rahat-Rozenbloom et al. 2017). Based on our results, this might be caused by inhibition of colonic octanoyl ghrelin release. Other studies failed to see any effects on plasma ghrelin levels after increased dietary fibre intake (Cluny et al. 2015, Steensels et al. 2017). However, future studies should consider measuring luminal, fecal and/or plasma SCFAs and their functional effects at different time points, since differences might only be evident at a certain time of day.

We showed that the circadian clock dictates rhythms in SCFAs and plays a role in SCFA-stimulated ghrelin release. Deletion of the core clock gene Bmal1 abolished fluctuations in plasma and caecal SCFA concentrations and abolished the effects of SCFAs on gastric and colonic octanoyl ghrelin release. To investigate whether this was due to the arrhythmic food intake pattern in Bmal1\%- mice, we restricted Bmal1- mice's access to food to the dark phase. It has been shown that giving access to food only during the dark phase restored rhythms in the microbiota of arrhythmic Per1/2-I- mice (Thaiss et al. 2014). Nighttime restricted feeding in Bmal1 $-/$ mice restored SCFA fluctuations in the caecum, but did not restore them in the plasma, indicating that BMAL1 might play a role in SCFA transport from the lumen of the gastrointestinal tract to the plasma.

Furthermore, night-time restricted feeding abolished the inhibitory effect of SCFAs on gastric octanoyl ghrelin release observed in ad libitum-fed Bmal1 ${ }^{-1}$ mice at ZT 4, although it did not restore the stimulation observed in WT mice. In contrast, RF of Bmal1 $1-$ mice completely restored the inhibitory effect of SCFAs on colonic octanoyl ghrelin release at ZT 4, to the same extent as the inhibition observed in WT mice. Additionally, Clock mRNA expression was upregulated, compared to both WT and Bmal1 - mice, indicating that night-time restricted feeding could affect the circadian system present in the colonic mucosa. Further studies should elucidate whether this could explain the restoration of the effect of SCFAs on octanoyl ghrelin release. A limitation of the study is that we did not include a WT RF group. We can therefore not conclude that night-time restricted feeding, normalized 
the effects in Bmal1 - mice but only that they counteracted the clock disrupting effects of the absence of Bmal1 ${ }^{-\%}$. In addition, tissue was not obtained under constant conditions (i.e. fasting for two 24-h cycles, constant darkness) for ethical reasons. Therefore, the true circadian nature of these diurnal findings remains to be determined. However, our results already showed that RF can be used to counteract the consequences of clock disruption due to the absence of BMAL1. We cannot make any statements whether this also resulted in a normalization of the effects observed in Bmal1 ${ }^{-}$mice.

Night-time restricted feeding has been shown to keep clock-disrupted mice healthy, preventing obesity and metabolic syndrome, even when fed a high-fat diet (Chaix et al. 2019b). Although time-restricted eating (TRE) in humans is less well studied, the first reports indicate that restricting food intake induces beneficial metabolic effects (improved insulin sensitivity, decreased blood pressure, decreased ghrelin and appetite), both in lean and obese individuals (Chaix et al. 2019a, Ravussin et al. 2019). Further studies are needed to investigate the potential role of the microbiota and SCFAs in these effects and to elucidate whether time-restricted eating could be used to counteract the deleterious effects of clock disruption by, for example, shift work.

\section{Supplementary materials}

This is linked to the online version of the paper at https://doi.org/10.1530/ JOE-20-0011.

\section{Declaration of interest}

The authors declare that there is no conflict of interest that could be perceived as prejudicing the impartiality of the research reported.

\section{Funding}

This work was supported by a Methusalem grant from the KU Leuven. The funder of the study had no role in study design, data collection, data analysis, data interpretation or writing of the report.

\section{Ethical approval}

Ethical Committee for Animal Experimentation of the KU Leuven.

\section{Author contribution statement}

A S, L D, K V, J T and I D conceived and designed the experiments. A S, L D and S S performed the experiments. A S and I D analysed the results and wrote the manuscript. All authors reviewed the manuscript.

\section{Acknowledgements}

The authors thank Theo Thijs, Linda Nys and Greet Vandermeulen for their skilful technical assistance.

\section{References}

Avau B, Carbone F, Tack J \& Depoortere I 2013 Ghrelin signaling in the gut, its physiological properties, and therapeutic potential. Neurogastroenterology and Motility 25 720-732. (https://doi. org/10.1111/nmo.12193)

Bodosi B, Gardi J, Hajdu I, Szentirmai E, Obal Jr F \& Krueger JM 2004 Rhythms of ghrelin, leptin, and sleep in rats: effects of the normal diurnal cycle, restricted feeding, and sleep deprivation. American Journal of Physiology: Regulatory, Integrative and Comparative Physiology 287 R1071-R1079. (https://doi.org/10.1152/ajpregu.00294.2004)

Callahan HS, Cummings DE, Pepe MS, Breen PA, Matthys CC \& Weigle DS 2004 Postprandial suppression of plasma ghrelin level is proportional to ingested caloric load but does not predict intermeal interval in humans. Journal of Clinical Endocrinology and Metabolism 89 1319-1324. (https://doi.org/10.1210/jc.2003-031267)

Cani PD, Dewever C \& Delzenne NM 2004 Inulin-type fructans modulate gastrointestinal peptides involved in appetite regulation (glucagonlike peptide-1 and ghrelin) in rats. British Journal of Nutrition 92 521-526. (https://doi.org/10.1079/bjn20041225)

Chaix A, Manoogian ENC, Melkani GC \& Panda S 2019a Time-restricted eating to prevent and manage chronic metabolic diseases. Annual Review of Nutrition 39 291-315. (https://doi.org/10.1146/annurevnutr-082018-124320)

Chaix A, Lin T, Le HD, Chang MW \& Panda S 2019b Time-restricted feeding prevents obesity and metabolic syndrome in mice lacking a circadian clock. Cell Metabolism 29 303.e4-319.e4. (https://doi. org/10.1016/j.cmet.2018.08.004)

Cluny NL, Eller LK, Keenan CM, Reimer RA \& Sharkey KA 2015 Interactive effects of oligofructose and obesity predisposition on gut hormones and microbiota in diet-induced obese rats. Obesity $\mathbf{2 3}$ 769-778. (https://doi.org/10.1002/oby.21017)

Crispim CA, Waterhouse J, Damaso AR, Zimberg IZ, Padilha HG, Oyama LM, Tufik S \& de Mello MT 2011 Hormonal appetite control is altered by shift work: a preliminary study. Metabolism: Clinical and Experimental 60 1726-1735. (https://doi.org/10.1016/j. metabol.2011.04.014)

Cummings DE, Purnell JQ, Frayo RS, Schmidova K, Wisse BE \& Weigle DS 2001 A preprandial rise in plasma ghrelin levels suggests a role in meal initiation in humans. Diabetes 50 1714-1719. (https://doi. org/10.2337/diabetes.50.8.1714)

den Besten G, van Eunen K, Groen AK, Venema K, Reijngoud DJ \& Bakker BM 2013 The role of short-chain fatty acids in the interplay between diet, gut microbiota, and host energy metabolism. Journal of Lipid Research 54 2325-2340. (https://doi.org/10.1194/jlr.R036012)

Dibner C 2020 The importance of being rhythmic: living in harmony with your body clocks. Acta Physiologica 228 e13281. (https://doi. org/10.1111/apha.13281)

Eberle JA, Widmayer P \& Breer H 2014 Receptors for short-chain fatty acids in brush cells at the 'gastric groove'. Frontiers in Physiology 5152. (https://doi.org/10.3389/fphys.2014.00152)

Ebino KY 1993 Studies on coprophagy in experimental animals. Jikken Dobutsu: Experimental Animals 42 1-9. (https://doi.org/10.1538/ expanim1978.42.1_1)

EFSA 2014 EFSA Panel on Food additives and Nutrient Sources added to Food (ANS). Scientific Opinion on the re-evaluation of propionic acid (E 280), sodium propionate (E 281), calcium propionate (E 282) and potassium propionate (E 283) as food additives. EFSA Journal 123779. (https://doi.org/10.2903/j.efsa.2014.3779) 
Engelstoft MS, Park WM, Sakata I, Kristensen LV, Husted AS, OsborneLawrence S, Piper PK, Walker AK, Pedersen MH, Nohr MK, et al. 2013 Seven transmembrane $\mathrm{G}$ protein-coupled receptor repertoire of gastric ghrelin cells. Molecular Metabolism 2 376-392. (https://doi. org/10.1016/j.molmet.2013.08.006)

Foster-Schubert KE, Overduin J, Prudom CE, Liu J, Callahan HS, Gaylinn BD, Thorner MO \& Cummings DE 2008 Acyl and total ghrelin are suppressed strongly by ingested proteins, weakly by lipids, and biphasically by carbohydrates. Journal of Clinical Endocrinology and Metabolism 93 1971-1979. (https://doi.org/10.1210/jc.2007-2289)

Gutierrez JA, Solenberg PJ, Perkins DR, Willency JA, Knierman MD, Jin Z, Witcher DR, Luo S, Onyia JE \& Hale JE 2008 Ghrelin octanoylation mediated by an orphan lipid transferase. PNAS 105 6320-6325. (https://doi.org/10.1073/pnas.0800708105)

Hass N, Schwarzenbacher K \& Breer H 2007 A cluster of gustducinexpressing cells in the mouse stomach associated with two distinct populations of enteroendocrine cells. Histochemistry and Cell Biology 128 457-471. (https://doi.org/10.1007/s00418-007-0325-3)

Hemmeryckx B, Himmelreich U, Hoylaerts MF \& Lijnen HR 2011 Impact of clock gene Bmal1 deficiency on nutritionally induced obesity in mice. Obesity 19 659-661. (https://doi.org/10.1038/oby.2010.266)

Ho CW, Lazim AM, Fazry S, Zaki UKHH \& Lim SJ 2017 Varieties, production, composition and health benefits of vinegars: a review. Food Chemistry 221 1621-1630. (https://doi.org/10.1016/j. foodchem.2016.10.128)

Iwakura H, Li Y, Ariyasu H, Hosoda H, Kanamoto N, Bando M, Yamada G, Hosoda K, Nakao K, Kangawa K, et al. 2010 Establishment of a novel ghrelin-producing cell line. Endocrinology 151 2940-2945. (https:// doi.org/10.1210/en.2010-0090)

Janssen S, Laermans J, Verhulst PJ, Thijs T, Tack J \& Depoortere I 2011 Bitter taste receptors and $\alpha$-gustducin regulate the secretion of ghrelin with functional effects on food intake and gastric emptying. PNAS 108 2094-2099. (https://doi.org/10.1073/pnas.1011508108)

Janssen S, Laermans J, Iwakura H, Tack J \& Depoortere I 2012 Sensing of fatty acids for octanoylation of ghrelin involves a gustatory G-protein. PLoS ONE 7 e40168. (https://doi.org/10.1371/journal. pone.0040168)

Karlsson B, Knutsson A \& Lindahl B 2001 Is there an association between shift work and having a metabolic syndrome? Results from a population based study of 27,485 people. Occupational and Environmental Medicine 58 747-752. (https://doi.org/10.1136/ oem.58.11.747)

Koh A, De Vadder F, Kovatcheva-Datchary P \& Backhed F 2016 From dietary fiber to host physiology: short-chain fatty acids as key bacterial metabolites. Cell 165 1332-1345. (https://doi.org/10.1016/j. cell.2016.05.041)

Kojima M, Hosoda H, Date Y, Nakazato M, Matsuo H \& Kangawa K 1999 Ghrelin is a growth-hormone-releasing acylated peptide from stomach. Nature $\mathbf{4 0 2}$ 656-660. (https://doi.org/10.1038/45230)

Kondratov RV, Kondratova AA, Gorbacheva VY, Vykhovanets OV \& Antoch MP 2006 Early aging and age-related pathologies in mice deficient in BMAL1, the core componentof the circadian clock. Genes and Development 20 1868-1873. (https://doi.org/10.1101/ gad.1432206)

Koyama H, Iwakura H, Dote K, Bando M, Hosoda H, Ariyasu H, Kusakabe T, Son C, Hosoda K, Akamizu T, et al. 2016 Comprehensive profiling of GPCR expression in ghrelin-producing cells. Endocrinology 157 692-704. (https://doi.org/10.1210/en.2015-1784)

Laermans J \& Depoortere I 2016 Chronobesity: role of the circadian system in the obesity epidemic. Obesity Reviews 17 108-125.

Laermans J, Vancleef L, Tack J \& Depoortere I 2015 Role of the clock gene Bmal1 and the gastric ghrelin-secreting cell in the circadian regulation of the ghrelin-GOAT system. Scientific Reports 516748.

Le Poul E, Loison C, Struyf S, Springael JY, Lannoy V, Decobecq ME, Brezillon S, Dupriez V, Vassart G, Van Damme J, et al. 2003 Functional characterization of human receptors for short chain fatty acids and their role in polymorphonuclear cell activation. Journal of Biological Chemistry 278 25481-25489. (https://doi.org/10.1074/jbc. M301403200)

Leone V, Gibbons SM, Martinez K, Hutchison AL, Huang EY, Cham CM, Pierre JF, Heneghan AF, Nadimpalli A, Hubert N, et al. 2015 Effects of diurnal variation of gut microbes and high-fat feeding on host circadian clock function and metabolism. Cell Host and Microbe $\mathbf{1 7}$ 681-689. (https://doi.org/10.1016/j.chom.2015.03.006)

Lu X, Zhao X, Feng J, Liou AP, Anthony S, Pechhold S, Sun Y, Lu H \& Wank S 2012 Postprandial inhibition of gastric ghrelin secretion by long-chain fatty acid through GPR120 in isolated gastric ghrelin cells and mice. American Journal of Physiology: Gastrointestinal and Liver Physiology 303 G367-G376. (https://doi.org/10.1152/ ajpgi.00541.2011)

McNabney SM \& Henagan TM 2017 Short chain fatty acids in the colon and peripheral tissues: a focus on butyrate, colon cancer, obesity and insulin resistance. Nutrients 9 E1348. (https://doi.org/10.3390/ nu9121348)

Mohawk JA, Green CB \& Takahashi JS 2012 Central and peripheral circadian clocks in mammals. Annual Review of Neuroscience $\mathbf{3 5}$ 445-462. (https://doi.org/10.1146/annurev-neuro-060909153128)

Mukherji A, Kobiita A, Ye T \& Chambon P 2013 Homeostasis in intestinal epithelium is orchestrated by the circadian clock and microbiota cues transduced by TLRs. Cell 153 812-827. (https://doi.org/10.1016/j. cell.2013.04.020

Müller TD, Nogueiras R, Andermann ML, Andrews ZB, Anker SD, Argente J, Batterham RL, Benoit SC, Bowers CY, Broglio F, et al. 2015 Ghrelin. Molecular Metabolism 4 437-460. (https://doi.org/10.1016/j. molmet.2015.03.005)

Nelson W, Tong YL, Lee JK \& Halberg F 1979 Methods for cosinorrhythmometry. Chronobiologia 6 305-323.

Padmanabhan P, Grosse J, Asad AB, Radda GK \& Golay X 2013 Gastrointestinal transit measurements in mice with 99mTc-DTPAlabeled activated charcoal using NanoSPECT-CT. EJNMMI Research 3 60. (https://doi.org/10.1186/2191-219X-3-60)

Pan A, Schernhammer ES, Sun Q \& Hu FB 2011 Rotating night shift work and risk of type 2 diabetes: two prospective cohort studies in women. PLoS Medicine 8 e1001141. (https://doi.org/10.1371/journal. pmed.1001141)

Panda S 2016 Circadian physiology of metabolism. Science $\mathbf{3 5 4}$ 1008-1015. (https://doi.org/10.1126/science.aah4967)

Partch CL, Green CB \& Takahashi JS 2014 Molecular architecture of the mammalian circadian clock. Trends in Cell Biology 24 90-99. (https:// doi.org/10.1016/j.tcb.2013.07.002)

Rahat-Rozenbloom S, Fernandes J, Cheng J \& Wolever TMS 2017 Acute increases in serum colonic short-chain fatty acids elicited by inulin do not increase GLP-1 or PYY responses but may reduce ghrelin in lean and overweight humans. European Journal of Clinical Nutrition $\mathbf{7 1}$ 953-958. (https://doi.org/10.1038/ejcn.2016.249)

Ravussin E, Beyl RA, Poggiogalle E, Hsia DS \& Peterson CM 2019 Early time-restricted feeding reduces appetite and increases fat oxidation but does not affect energy expenditure in humans. Obesity $\mathbf{2 7}$ 1244-1254. (https://doi.org/10.1002/oby.22518)

Reinke H \& Asher G 2019 Crosstalk between metabolism and circadian clocks. Nature Reviews: Molecular Cell Biology 20 227-241. (https://doi. org/10.1038/s41580-018-0096-9)

Schiavo-Cardozo D, Lima MM, Pareja JC \& Geloneze B 2013 Appetiteregulating hormones from the upper gut: disrupted control of xenin and ghrelin in night workers. Clinical Endocrinology 79 807-811. (https://doi.org/10.1111/cen.12114)

Segers A, Desmet L, Thijs T, Verbeke K, Tack J \& Depoortere I 2019 The circadian clock regulates the diurnal levels of microbial short-chain fatty acids and their rhythmic effects on colon contractility in mice. Acta Physiologica 225 e13193. (https://doi. org/10.1111/apha.13193) https://joe.bioscientifica.com

https://doi.org/10.1530/JOE-20-0011 (c) 2020 Society for Endocrinology Published by Bioscientifica Ltd. Printed in Great Britain 
Smith HW 1965 The development of the flora of the alimentary tract in young animals. Journal of Pathology and Bacteriology 90 495-513. (https://doi.org/10.1002/path.1700900218)

Steensels S \& Depoortere I 2018 Chemoreceptors in the gut. Annual Review of Physiology 80 117-141. (https://doi.org/10.1146/annurevphysiol-021317-121332)

Steensels S, Cools L, Avau B, Vancleef L, Farre R, Verbeke K \& Depoortere I 2017 Supplementation of oligofructose, but not sucralose, decreases high-fat diet induced body weight gain in mice independent of gustducin-mediated gut hormone release. Molecular Nutrition and Food Research 61 1600716. (https://doi.org/10.1002/mnfr.201600716)

Tahara Y, Yamazaki M, Sukigara H, Motohashi H, Sasaki H, Miyakawa H, Haraguchi A, Ikeda Y, Fukuda S \& Shibata S 2018 Gut microbiotaderived short chain fatty acids induce circadian clock entrainment in mouse peripheral tissue. Scientific Reports 8 1395. (https://doi. org/10.1038/s41598-018-19836-7)

Tarini J \& Wolever TM 2010 The fermentable fibre inulin increases postprandial serum short-chain fatty acids and reduces free-fatty acids and ghrelin in healthy subjects. Applied Physiology, Nutrition, and Metabolism 35 9-16. (https://doi.org/10.1139/H09-119)

Thaiss CA, Zeevi D, Levy M, Zilberman-Schapira G, Suez J, Tengeler AC, Abramson L, Katz MN, Korem T, Zmora N, et al. 2014 Transkingdom control of microbiota diurnal oscillations promotes metabolic homeostasis. Cell 159 514-529. (https://doi.org/10.1016/j. cell.2014.09.048)
Vancleef L, Van Den Broeck T, Thijs T, Steensels S, Briand L, Tack J \& Depoortere I 2015 Chemosensory signalling pathways involved in sensing of amino acids by the ghrelin cell. Scientific Reports 515725.

Vancleef L, Thijs T, Baert F, Ceulemans LJ, Canovai E, Wang Q, Steensels S, Segers A, Farre R, Pirenne J, et al. 2018 Obesity impairs oligopeptide/amino acid-induced ghrelin release and smooth muscle contractions in the human proximal stomach. Molecular Nutrition and Food Research 62 1700804. (https://doi.org/10.1002/mnfr.201700804) Vandesompele J, De Preter K, Pattyn F, Poppe B, Van Roy N, De Paepe A $\&$ Speleman F 2002 Accurate normalization of real-time quantitative RT-PCR data by geometric averaging of multiple internal control genes. Genome Biology 3 RESEARCH0034. (https://doi.org/10.1186/ gb-2002-3-7-research0034)

Wang Q, Liszt KI, Deloose E, Canovai E, Thijs T, Farre R, Ceulemans LJ, Lannoo M, Tack J \& Depoortere I 2019 Obesity alters adrenergic and chemosensory signaling pathways that regulate ghrelin secretion in the human gut. FASEB Journal 4 4907-4920.

Yang J, Brown MS, Liang G, Grishin NV \& Goldstein JL 2008 Identification of the acyltransferase that octanoylates ghrelin, an appetite-stimulating peptide hormone. Cell 132 387-396. (https:// doi.org/10.1016/j.cell.2008.01.017)

Yildiz BO, Suchard MA, Wong ML, McCann SM \& Licinio J 2004 Alterations in the dynamics of circulating ghrelin, adiponectin, and leptin in human obesity. PNAS 101 10434-10439. (https://doi. org/10.1073/pnas.0403465101)

Received in final form 12 January 2020

Accepted 7 February 2020

Accepted Manuscript published online 11 February 2020 (c) 2020 Society for Endocrinology Published by Bioscientifica Ltd. 